\title{
MEMBANGUN "SISTEM DINAMIS UNTUK MENGHITUNG DEBIT PUNCAK" (SDDP) DENGAN MENGGUNAKAN STELLA VERSI 9.0.2 (Uji Aplikasi Untuk Wilayah Banjir di Kecamatan Makasar Jakarta Timur)
}

\author{
R. Haryoto Indriatmoko \\ Pusat Pengkajian dan Penerapan Teknologi Lingkungan, BPP Teknologi \\ Jl. M.H. Thamrin 8 Jakarta Pusat
}

\begin{abstract}
Peak Discharge Dinamyc System (SDDP) is a program which apply to calculate peak of discharge a catchment area with area and rain fall intensity as parameters, with limited to maximal $50 \mathrm{~km} 2$ area and $100 \mathrm{~mm} / \mathrm{hour}$ rain fall intensity. This program is develop by using System Dinamyc Stella version 9.0.2. Steps taken are, first by calculate runoff cooeficient use Bridge-Branch method and then calculate peak discharge with rational method. This program is tested on sub-catcment Makassar, East Jakarta and compare the result of the program with manual calculation, and concluded that no deviation between those 2 methods, and even more the SDDP program provide prediction of peak discharge with variable $C$ value and data of calculation peak discharge with SDDP program presented in graphic and tabulation as well.
\end{abstract}

Key words : Model, Sistem Dinamis, Stella, Banjir, Debit Puncak, Koefisien Aliran, Prediksi, Jakarta Timur

\section{PENDAHULUAN}

\subsection{Latar Belakang}

Saat ini informasi sudah menjadi suatu kebutuhan penting bagi manusia, dalam rangka mendapatkan kenyamanan hidup mulai dari informasi mengenai meteorologi dan geofisika (terutama berkaitan dengan masalah transportasi), perubahan penggunaan lahan, banjir, tanah longsor, bencana, kekeringan, sampai masalah ekonomi, politik, sosial dan budaya. Informasi sangat dibutuhkan terutama bagi para pengambil keputusan seperti pemerintah, pelaku ekonomi dan bisnis, politikus, ahli hukum atau para peneliti dan kalangan akademis. Kebutuhan akan Informasi semakin berpacu dengan waktu agar dapat dimanfaatkan atau disampaikan kepada pengguna.

Salah satu cara untuk mendapatkan informasi yang cepat terutama yang berbasis pada model sistem dinamik dapat dilakukan dengan memanfaatkan software Stella. Model ini dapat mensimulasikan perubahan yang terjadi dan hasilnya dapat ditampilkan dalam suatu hasil analisis berupa grafis dan tabulasi. Analisis grafis akan dapat menggambarkan hubungan antar parameter atau variabel dalam bentuk grafis. Tren grafis bisa ditampilkan dalam grafis garis, batang dari variabel yang saling berhubungan. Analisis tabulasi menggambarkan hubungan antar variabel dalam wujud angka atau numeris ${ }^{1)}$.

Model Stella ini akan digunakan untuk perhitungan pada kondisi saat ini dan prediksi hasil dari debit puncak pada suatu Daerah Aliran Sungai (DAS). Untuk dapat menghitung besarnya debit puncak dari suatu DAS syarat utama adalah data intensitas hujan yang digunakan berasal dari hujan dengan durasi hujan yang sama dengan waktu konsentrasi (Tc). Jika syarat tersebut dapat dipenuhi maka akan diperoleh hasil perhitungan debit puncak maksimum ${ }^{3)}$. Alasan dari dipilinnya sistem dinamis Stella ini digunakan untuk menganalisis besarnya debit puncak adalah kemampuannya dalam membuat "looping" dari pembacaan data secara tersusun dan bergantian. Dari kemampuan pembacaan secara tersusun dan bergantian inilah sistem dinamis tersebut diaplikasikan dalam Model SDDP ini.

Parameter yang disajikan untuk menghitung besarnya koefisien aliran dari metode Bridge-Branch (IEA, 1987) ini disusun secara klas dan masing masing parameter diberi bobot menurut besarnya faktor pengaruh (Lihat Lampiran 1). Nilai koefisien aliran yang semakin besar disuport oleh klas bobot yang juga semakin besar dan untuk nilai koefisien aliran yang kecil didapat dari parameter fisik dan meteorologi yang berasal dari bobot yang kecil. Sistem dinamis Stella ini dapat digunakan untuk menghitung besarnya koefisien aliran dengan cara perhitungan secara tersusun secara kombinasi dan saling bergantian. Hasilnya adalah deret koefisien aliran C dari 0,1 sampai 1 . Deret koefisien aliran dari 0,1 sampai 1 inilah yang digunakan untuk membuat deret yang sama dari debit puncak.

Deret hubungan antara koefisien aliran dengan debit puncak inilah yang digunakan sebagai data untuk dapat memprediksi besarnya debit puncak dari $\mathrm{C}$ hasil prediksi. Perubahan 
besarnya koefisien aliran disebabkan atas adanya suatu dinamika dari parameter fisik dan meteorologi yang ada dalam DAS, yaitu sebagai akibat dari perubahan penggunaan lahan dan intensitas hujan.

Pengaruh faktor fisik dan meteorologi dalam suatu DAS yang mempengaruhi besarnya koefisien aliran adalah perubahan penggunaan lahan/tutupan lahan, "storage" atau timbunan dari faktor-faktor drainase, kemiringan lereng dan intensitas hujan ini adalah faktor yang paling berpengaruh terhadap koefisien aliran (C). Koefisien aliran yang semakin besar dari suatu DAS akan, yang ditunjukkan dengan semakin cepatnya air hujan yang berubah menjadi aliran ${ }^{3)}$.

Koefisien aliran mempunyai peranan yang sangat penting yaitu sebagai indikator fisik yang mempengaruhi proses aliran air dalam dalam DAS. Jika koefisien aliran suatu DAS kecil kurang dari $50 \%$ itu merupakan suatu tanda bahwa DAS dalam keadaan yang cukup baik sedangkan jika lebih dari $50 \%$ maka kondisinya kurang baik, karena DAS kurang dapat menyimpan air hujan. Koefisien aliran juga dapat dipakai sebagai tolok ukur untuk mengevaluasi aliran dalam kaitannya dengan aktifitas yang dilakukan dalam DAS (misalnya kegiatan pengelolaan DAS).

Fungsi penting lainnya dari koefisien aliran adalah dalam memprediksi besarnya debit puncak. Sebagai indikator aliran permukaan biasanya dipakai dalam menentukan debit puncak suatu banjir, sedangkan sebagai tolok ukur dalam mengevaluasi pengelolaan DAS, koefisien aliran dipakai sebagai salah satu indikator pengaruh dari suatu upaya Pengelolaan DAS. Jika dari hasil upaya pengelolaan DAS telah menyebabkan nilai koefisien aliran yang semakin mengecil maka ini merupakan indikasi bahwa upaya tersebut telah memberikan hasil. Sebaliknya jika upaya yang dilakukan tidak menjukan adanya nilai $\mathrm{C}$ yang semakin berkurang maka upaya yang telah dilakukan belum mengarah pada keberhasilan.

\subsection{Tujuan}

Tujuan dari penulisan ini adalah mengaplikasikan suatu model dinamis menggunakan Sistem Dinamis Stella untuk menghitung debit puncak dari sebuah DAS dengan luas kurang dari $50 \mathrm{Km}^{2}$ sebagai akibat dari perubahan penggunan lahan atau peningkatan nilai $\mathrm{C}$. Model ini dibangun dengan metode perhitungan koefisien aliran yang dikembangkan oleh Bridge-Branch (IEA, 1987). Membandingkan hasilnya hitungan dengan model SDDP dengan analisis debit puncak dengan menggunakan sampel dari DAS yang dipilih.

\subsection{Metodologi}

\subsubsection{Langkah-langkah}

a. Studi Pustaka atau pendalaman model dinamik Stell Versi 9. Mendalami manual dari model, mulai dari cara operasi, pemakaian formula dan membuat model dan testing model dan mengaplikasikannya untuk suatu DAS dengan luas kurang dari $50 \mathrm{Km}^{2}$. Perhitungan debit puncak secara cepat. Hasilnya berupa analisis dalam bentuk grafik dan tabel.

b. Tahap Perolehan/Pengumpulan Data. Data diperoleh dari data sekunder sebagai data tes, dari sebuah DAS yang sudah dianalisis intensitas hujan dan durasi hujan. Model diaplikasikan pada wilayah banjir di Kecamatan Makasar Jakarta Timur, dari subsub DAS kecil di Jakarta Timur yang merupakan wilayah banjir lokal. Sub-sub DAS ini mempunyai luas area kurang dari $50 \mathrm{Km}^{2}$, seperti yang disyaratkan dalam metode Bridge-Branch, data bobot untuk masingmasing parameter.

c. Dinamika model. Parameter untuk relief, storage dan karakteristik, tutupan lahan dan intensitas hujan merupakan parameter yang menentukan dalam koefisien aliran. Parameter tersebut digunakan sebagai parameter dinamis dari model untuk menunjukkan adanya aktifitas kegiatan dalam DAS yang mengasumsikan perubahan lahan. Perubahan $\mathrm{C}$ dianggap sebagai akibat dari perubahan pengunaan lahan/tutupan lahan, perubahan storage/timbunan/drainese, dan kemiringan lereng.

d. Hasil akhir. Hasil dari "running" model disajikan dalam bentuk grafik dan tabel.

e. Uji hasil. Uji hasil akan dilakukan dengan membandingkan hasil perhitungan antara Model SDDP dengan perhitungan debit puncak dari sampel uji.

Untuk menghitung besarnya koefisien aliran ( C ) ditetapkan dengan pendekatan Metode Bridge-Branch (IEA, 1987). Berdasarkan metode tersebut parameter fisik nan non fisik yang mempengaruhi koefisien aliran adalah:

1) Intensitas Hujan.

2) Kemiringan lereng/relief

3) Kapasitas penampungan/storage

4) Karakteristik dan tutupan lahan/"ground characteristic".

Untuk mengetahui besarnya debit puncak maka nilai $\mathrm{C}$ dapat dihitung dengan Metode tersebut. Pada sampel uji besarnya nilai 
C dapat dilihat pada Tabel 2. Untuk memprediksi besarnya debit puncak dilakukan dengan cara melihat dari Lampiran dari output Model SDDP, pada kolom debit puncak dan pada $C$ hasil prediksi. Sebagai contoh diambil dari kasus yang ada di sub-sub DAS Halim. Besarnya debit puncak pada periode ulang 2 tahun dengan $\mathrm{C}$ hitung (saat ini yaitu 0,65 ) adalah $4,92 \mathrm{~m} 3 / \mathrm{dt}$. Maka dapat dilakukan suatu prediksi terhadap debit puncak pada saat $C$ prediksi 0,80 sehingga akan diperoleh besarnya debit puncak dengan periode ulang 2 tahun yaitu sebesar $6,05 \mathrm{~m}^{3} / \mathrm{dt}$.

Untuk dapat menghitung besarnya koefisien aliran dari suatu DAS keempat parameter tersebut di beri nilai bobot. Total bobot pada kondisi maksimal adalah 100 atau kalau dinyatakan dalam koefisien aliran adalah 1 . Dalam kondisi maksimal (C) besar tutupan lahan memberikan bobot $45 \%$, Intensitas hujan $35 \%$, Kemiringan lereng dan timbunan permukaan masing-masing memberikan bobot $10 \%$ dari besarnya koefisien aliran. Adapun besarnya Koefisien Aliran yang didasarkan atas keempat parameter fisik dan meteorologi yang telah disebutkan dimuka. Tabulasi parameter fisik dan meteorologi dari metode Bridge-Branch dapat dilihat pada Lampiran 1.

Model SDDP ini sebaiknya digunakan untuk DAS dengan luas area kurang dari $50 \mathrm{Km}^{2}$. Adapun yang mendasari alasan tersebut adalah jika DAS yang akan dianalisis mempunyai luas area lebih besar dari $50 \mathrm{Km}^{2}$, maka nilai $C$ yang didapat akan kurang dari $50 \%$, sedang untuk nilai C lebih $80 \%$ hanya akan dapat dicapai jika intensitas hujan tinggi dan mencakup 90\% DAS (dimana kondisi Antecendent Precipitation Index dalam keadaan jenuh). Alasan lainnya adalah jika luas area DAS lebih besar dari $50 \mathrm{~km} 2$, adalah adanya keseragaman hujan terhadap waktu dan ruang yang sulit dicapai pada DAS lebih besar dari $50 \mathrm{~km}^{2}$.

\subsubsection{Rumus Yang Digunakan}

Untuk mendapatkan besarnya koefisien aliran ( C) dari suatu DAS dilakukan dengan menjumlahkan keempat parameter fisik dan paramete klimatologinya kemudian membagi dengan 100. Besarnya koefisien aliran dengan menggunakan metode tersebut adalah antara 0,1 dan maksimum 1.

Untuk menghitung Debit Puncak (Qp) dilakukan dengan menggunakan metode rasional, dimana Qp tersebut diperoleh dengan metode rasional ${ }^{3)}$ :

$$
\text { Qp }=0,278 \text { C.I.A } \quad \mathrm{m}^{3} / \mathrm{dt}
$$

Keterangan:

$\mathrm{Qp} \quad=$ Debit puncak $\left(\mathrm{m}^{3} / \mathrm{dt}\right)$

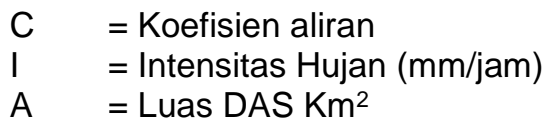

\section{APLIKASI MODEL STELLA}

Model dinamik yang tersedia di pasar adalah Dynamo, Vensim, I-Think, Powersim dan Stella. Software model dinamik tersebut mempunyai keunggulan dan kekurangan masingmasing. System dinamik yang digunakan untuk perhitungan Debit puncak ini mengunakan Stella Versi-9. Langkah-langkah yang dilakukan untuk memodelkan perhitungan debit puncak adalah sebagai berikut:

1. Merencanakan model yang dimulai dengan pembuatan Stock, Flow, Converter dan Konektor, dan memberikan indikator atau keterangan untuk masing masing Stock, dan Converter.

2. Stock dinyatakan sebagai hasil akumulasi, fungsinya untuk menyimpan informasi parameter yang masuk dan keluar.

3. Flow berfungsi sebagai aliran yang akan mengisi dan mengalirkan stock. Dalam aplikasi ini flow digunakan untuk menyatakan hasil dari perhitungan Debit Puncak, rumus dasar dari metode rasional untuk debit puncak dibuat dalam flow ini.

4. Converter, berfungsi untuk menyimpan konstanta atau input suatu persamaan atau untuk fungsi logika. Pada model ini konverter digunakan untuk memasukkan input intensitas hujan dan luas DAS. Sedangkan converter lainnya digunakan untuk memasukkan fungsi logika pada Bobot intensitas mulai dari tipe 1 sampai 7 dengan menggunakan fungsi logika IF THEN dan ELSE. Bobot 1-7 digunakan untuk pembobotan Intensitas hujan. Converter lainnya digunakan untuk menghitung nilai $\mathrm{C}$. Input $C$ ini diperoleh dengan melakukan penjumlahan bobot dari setiap parameter kemudian membaginya dengan 100 agar hasilnya antara 0,1 sampai 1 .

5. Dengan cara memasukkan nilai Intensitas hujan dan luas DAS, maka akan diperoleh besarnya debit puncak dari DAS tersebut.

6. Debit puncak dari suatu DAS akan dicapai jika Intensitas hujan yang digunakan diperoleh dari hujan yang terjadi dengan lama hujan sama dengan waktu konsentrasi. Untuk memperoleh data intensitas hujan yang dimaksud, dapat diperoleh dari data kurva Intensitas Durasi dan Frekuensi / Periode Ulang DAS bersangkutan. Untuk contoh uji terhadap Model SDDP pada sub-sub DAS di Kecamatan Makasar maka digunakan kurva IDF dari stasiun meteorologi Halim Perdana Kusuma. Kurva IDF tersebut terdapat pada Lampiran 4. 
Struktur model dan Formula dari model SDDP dapat dilihat pada Lampiran 2 dan Lampiran 3. Untuk dapat menghitung besarnya debit puncak dari suatu DAS dilakukan dengan cara memasukkan input numerik yang terdiri dari:

1. Input luas DAS dalam $\mathrm{km}^{2}$.

2. Input intensitas hujan dalam satuan mm/jam'

3. Syarat yang ditetapkan pada model ini adalah a. Luas DAS yang akan dianalisis adal $<=50$ $\mathrm{Km} 2$. b. Intensitas hujan maksimum adalah $<=100 \mathrm{~mm} / \mathrm{jam}$, jika memasukkan intensitas hujan lebih dari $100 \mathrm{~mm} / \mathrm{jam}$, maka oleh model intensitas hujan dianggap sebagai 100 $\mathrm{mm} / \mathrm{jam}$.

Setelah memasukkan kedua input tersebut kedalam model maka untuk "running" model ini dapat dilakukan dengan meng klik tanda ( ), hasilnya dapat dilihat dengan cara Tabel dan Grafik. Grafik yang dihasilkan menunjukkan hubungan antara Besarnya luas DAS, Intensitas hujan, koefisien aliran dan Debit Puncak. Hasil perhitungan selain ditunjukkan dalam bentuk grafik juga disajikan kedalam bentuk Tabel 1).

\section{HASIL DAN PEMBAHASAN}

Model SDDP akan diuji coba untuk menghitung debit puncak pada wilayah rawan genangan di Kecamatan Makasar Jakarta Timur. Wilayah Kecamatan Makasar terdiri dari lima kelurahan yaitu Kelurahan Makasar, Halim Perdana Kusuma, Cipinang Melayu, Kebon Pala dan Pinang Ranti. Luas Kecamatan mencapai 21,66 Ha. Wilayah ini secara administratif dibatasi di sebelah utara oleh Kecamatan Jatinegara, sebelah timur Pondok Gede dan Bekasi, sebelah selatan Kecamatan Cipayung dan Kodya Jakarta Timur, dan di sebelah barat Kecamatan Kramat Jati dan Kodya Jakarta Timur.

Di wilayah Kecamatan Makasar, kejadian banjir yang dapat menimbulkan genangan terjadi hampir tiap tahun sekali yaitu terjadi di Sub-sub DAS Halim dengan outlet di SMU 9, Sub-sub DAS Kamboja dengan outlet Bayu Ujung, Subsub DAS Jengki dengan outlet SD Inpres, Subsub DAS Supomo dengan outlet di Depnaker, Sub-sub DAS Pulo Gadel dan Sub-sub DAS Taman Harapan dengan outlet di Harapan 4. Luas masing-masing Sub-sub DAS dapat dilihat pada Tabel 1.2)

Tabel 1. Luas sub-sub DAS di Kecamatan Makasar

\begin{tabular}{|l|l|c|}
\hline No & Nama Sub-sub DAS & ${\text { Luas } \mathbf{k m}^{\mathbf{2}}}^{\text {Nam }}$ \\
\hline 1 & Halim & 0,29 \\
\hline 2 & Kamboja & 0.25 \\
\hline 3 & Jengki & 0.25 \\
\hline
\end{tabular}

\begin{tabular}{|l|l|c|}
\hline 4 & Supomo & 0.32 \\
\hline 5 & Pulo Gadel & 0.16 \\
\hline 6 & Taman Harapan & 0.41 \\
\hline \multicolumn{2}{|c|}{ Sumber: Meliza, G.R., 2006 } \\
\hline \multicolumn{2}{|c|}{}
\end{tabular}

Tata guna lahan di wilayah Kecamatan Makasar dialokasikan untuk perumahan (80\%), wilayah industri $(16,96 \%)$ dan digunakan untuk lainnya lapangan udara, golf, fasilitas sosial dan komplek TNI AU seluas 52,31\%. Topografi wilayah ini umumnya datar, dan timbunan permukaan dengan sistem drainase yang kurang lancar, jika hujan turun maka wilayah ini mudah timbul adanya genangan ${ }^{2}$.

Hasil perhitungan besarnya koefisien aliran secara tertimbang/menggunakan $C$ dari literatur terhadap keenam Sub-sub DAS dikecamatan Makasar adalah dapat dilihat pada Tabel 2. Hasil analisis terhadap intensitas hujan di sub-sub DAS di Kecamatan Makasar yang didasarkan atas hujan dengan intensitas hujan yang terjadi dengan durasi hujan sama dengan Tc adalah dapat dilihat pada Tabel 3.

Tabel 2. Hasil analisis Koefisien Aliran sub-sub DAS di Kecamatan Makasar

\begin{tabular}{|l|l|c|}
\hline No & Nama Sub-sub DAS & C \\
\hline 1 & Halim & 0,60 \\
\hline 2 & Kamboja & 0,59 \\
\hline 3 & Jengki & 0,62 \\
\hline 4 & Supomo & 0,61 \\
\hline 5 & Pulo Gadel & 0,61 \\
\hline 6 & Taman Harapan & 0,60 \\
\hline
\end{tabular}

Sumber: Meliza, G.R., 2006

Model SDDP yang dibangun kemudian diuji untuk menghitung debit puncak (Qp) dari 6 buah sub-sub das di wilayah Kecamatan Makasar. Hasil perhitungan debit puncak antara hasil "running Model SDDP dengan sampel uji dari sub-sub DAS yang ada di Kecamatan Makasar dapat dilihat pada Tabel 4.

Pada Tabel 4, debit puncak yang dihitung oleh Meliza (Meliza G.R., 2006) dibandingkan dengan SDDP terdapat perbedaan hasil. Hasil perhitungan debit puncak dengan menggunakan SDDP menunjukkan hasil yang lebih besar. Ini sebenarnya tidak menunjukkan adanya kesalahan hitung. Perbedaan tersebut terjadi karena nilai $C$ yang digunakan dalam model SDDP menggunakan nilai $C$ sebesar 0,65 . Nilai C sebesar 0,65 tersebut lebih banyak dipicu oleh intensitas hujan pada periode ulang 2 tahun pada interval $75-<100$ (Lampiran 1) yang memberikan bobot kontribusi dengan nilai 30 atau 0,30) dari nilai C yang didapat dari model SDDP. Perbedaan tersebut disebabkan oleh adanya pembobotan dalam Metode Bridge-Branch (IEA, 
1987), dimana range nilai $C$ tersebut berkisar antara 0,1 sampai 1 atau dengan interval 0,5 . Perhitungan $\mathrm{C}$ dalam sampel dihitung dari setiap penggunaan lahan dengan nilai $C$ yang diambil dari referensi. Hasilnya akan diperoleh nilai $C$ dengan interval perhitungan sampai 0,1 . Tabel 5 menjelaskan perbedaan antara $C$ sampel dan $C$ dari model SDDP, sehingga akan menghasilkan hasil hitungan yang berbeda.

Tabel 3. Intensitas hujan perioda ulang 2 tahun dan 5 tahun dari berbagai Tc pada sub-sub DAS di Kecamatan Makasar

\begin{tabular}{|l|l|c|c|c|}
\hline No & Nama Sub-sub DAS & $\begin{array}{c}\text { Tc } \\
\text { (jam) }\end{array}$ & $\begin{array}{c}\text { I } \\
2 \text { tahun } \\
\text { mm/jam }\end{array}$ & $\begin{array}{c}\text { I } \\
5 \text { tahun } \\
\text { mm/jam }\end{array}$ \\
\hline 1 & Halim & 0,34 & 93,87 & 116,4 \\
\hline 2 & Kamboja & 0,69 & 68,8 & 87,5 \\
\hline 3 & Jengki & 0,44 & 85,05 & 106,4 \\
\hline 4 & Supomo & 0,46 & 78,3 & 98 \\
\hline 5 & Pulo Gadel & 0,37 & 93,8 & 116,4 \\
\hline 6 & Taman Harapan & 0,7 & 98,75 & 111,2 \\
\hline \multicolumn{4}{|c|}{ Sumber: Meliza, G.R., 2006 }
\end{tabular}

Tabel 4. Hasil perhitungan debit puncak antara Sampel dan Model SDDP

\begin{tabular}{|l|l|c|c|c|}
\hline No & $\begin{array}{c}\text { Nama Sub-sub } \\
\text { DAS }\end{array}$ & $\begin{array}{c}\text { I } \\
2 \text { tahun } \\
\text { (jam) }\end{array}$ & $\begin{array}{c}\text { Qp }\left(^{*}\right) \\
2 \text { tahun } \\
\mathrm{m} 3 / \mathrm{dt}\end{array}$ & $\begin{array}{c}\text { QP- } \\
\text { SDDP } \\
2 \text { tahun } \\
\text { M3/dt }\end{array}$ \\
\hline 1 & Halim & 93,87 & 4,56 & 4,92 \\
\hline 2 & Kamboja & 68,8 & 2,83 & 2,87 \\
\hline 3 & Jengki & 85,05 & 3,69 & 3,84 \\
\hline 4 & Supomo & 78,3 & 4,28 & 4,53 \\
\hline 5 & Pulo Gadel & 93,8 & 2,53 & 2,71 \\
\hline 6 & Taman Harapan & 98,75 & 5,39 & 7,32 \\
\hline
\end{tabular}

${ }^{*}$ ) dilakukan oleh Meliza, G.R., 2006

Tabel 5. Besarnya Koefisien Aliran ( C ), antara Sampel dengan Model SDDP yang menghasilkan debit puncak

\begin{tabular}{|c|c|c|c|c|}
\hline No & $\begin{array}{c}\text { Nama Sub-sub } \\
\text { DAS }\end{array}$ & $\begin{array}{c}1 \\
2 \text { tahun } \\
\text { (jam) }\end{array}$ & $\begin{array}{c}C^{\star} \\
\text { Sampel }\end{array}$ & $\stackrel{C}{\mathrm{C}}$ \\
\hline 1 & Halim & 93,87 & 0,60 & 0,65 \\
\hline 2 & Kamboja & 68,8 & 0,59 & 0,65 \\
\hline 3 & Jengki & 85,05 & 0,62 & 0,65 \\
\hline 4 & Supomo & 78,3 & 0.61 & 0,65 \\
\hline 5 & Pulo Gadel & 93,8 & 0,61 & 0,65 \\
\hline 6 & Taman Harapan & 98,75 & 0,60 & 0,65 \\
\hline
\end{tabular}

Untuk dapat memprediksi besarnya debit puncak pada periode ulang 2 tahun dari sub-sub DAS Halim dapat dilakukan dengan membaca Tabel yang disajikan pada Lampiran 5. Jika karena aktifitas pembangunan menyebabkan terjadi perubahan penggunaan lahan sehingga berdasarkan hasil analisis terhadap koefisien aliran menjadi 0,80 maka jika ada hujan dengan intensitas sebesar 93,87 mm/jam maka besarnya debit puncak di sub-sub DAS Halim adalah 6,06 m3/dt (Lihat tabel pada Lampiran 5). Dengan mengetahui kemungkinan debit puncak yang akan terjadi maka akan dapat diantisipasi rancangan bangunan air yang akan didisain. Ini akan memberikan keuntungan secara teknis.

\section{PENUTUP}

Model SDDP dalam penggunaannya untuk menghitung debit puncak ternyata dapat dilakukan dengan cepat. Jika hasil perhitungan debit puncak yang dilakukan dengan menggunakan Model SDDP dibandingkan dengan metode perhitungan lainnya maka akan diperoleh hasil yang relatif sama atau tidak ada perbedaan pada nilai nilai $C$ sama terhadap hasil perhitungan yang dilakukan dengan metode lainnya.

Keuntungan yang ditawarkan dengan menggunakan model SDDP ini adalah dapat menghitung debit puncak secara serentak dengan berbagi koefisien aliran, yang disajikan dalam bentuk tabel dan grafik, sehingga memudahkan untuk analisis dan memprediksi debit puncak kedepan. Jika besarnya koefisien aliran dimasa yang akan datang dapat diketahui maka debit puncak yang akan terjadi dengan periode ulang tertentu akan dapat diketahui juga.

\section{DAFTAR PUSTAKA}

1. Agela B. Shiflet and George W Shift, 2006, Introduction to Computational Science: Modeling and Simulation for the Sciences, Princeton University Press.

2. Meliza, G.R, 2006. Evaluasi Sistem Drainase Pada Daerah Rawan Genangan di Wilayah Kecamatan Makasar Jakarta Timur, Teknik Lingkungan Universitas Trisakti, Jakarta.

3. The Institution of Engineers Australia, 1987, Australian Rainfall and Runoff. IEA National Headquarters: Australia. 


\section{LAMPIRAN}

Lampiran 1. Perkiraan besarnya koefisien aliran C menurut metode Bridge-Branch (IEA, 1987)

\begin{tabular}{|c|c|c|c|c|c|c|c|c|c|c|}
\hline $\begin{array}{l}\text { Intensitas } \\
\text { Hujan (mm/jam) }\end{array}$ & $\begin{array}{c}\text { Bobot } 35 \\
100\end{array}$ & $\begin{array}{l}\text { Bobot 3 } \\
75-<10\end{array}$ & & $\begin{array}{l}\text { 3obot } 25 \\
50-<75\end{array}$ & $\begin{array}{r}\text { Bobot } 1 \\
25-<50\end{array}$ & & $\begin{array}{l}\text { obot } 10 \\
2-<25\end{array}$ & $\begin{array}{r}\text { Bobc } \\
12\end{array}$ & & $\begin{array}{c}\text { Bobot } 0 \\
<12\end{array}$ \\
\hline Relief & \multicolumn{2}{|c|}{$\begin{array}{c}\text { Bobot } 10 \\
\text { Kemiringan }>15 \%\end{array}$} & \multicolumn{2}{|c|}{$\begin{array}{l}\text { Bobot } 5 \\
\text { Kemiringan } \\
8-15 \%\end{array}$} & \multicolumn{2}{|c|}{$\begin{array}{c}25-<50 \\
\text { Bobot } 5 \\
\text { Kemiringan } \\
4-8 \%\end{array}$} & \multicolumn{2}{|c|}{$\begin{array}{c}\text { Bobot } 0 \\
\text { Kemiringan } \\
1,5-4 \%\end{array}$} & & $\begin{array}{l}\text { Bobot } 0 \\
\text { Kemiringan } \\
0-1,5 \%\end{array}$ \\
\hline Storage & \multicolumn{3}{|c|}{$\begin{array}{c}\text { Bobot } 10 \\
\text { Tidak ada, sedikit } \\
\text { depresi permukaan, } \\
\text { anak sungai, limpasan } \\
\text { permukaan } \\
\text { mudah/cepat }\end{array}$} & \multicolumn{2}{|c|}{$\begin{array}{c}\text { Bobot } 10 \\
\text { Sistem drainase baik } \\
\text { dengan anak sungai }\end{array}$} & \multicolumn{3}{|c|}{$\begin{array}{c}\text { Bobot } 5 \\
\text { Limpasan permukaan } \\
\text { signifikan, kolam } \\
\text { persawahan atau } \\
\text { kolam }\end{array}$} & \multicolumn{2}{|c|}{$\begin{array}{c}\text { Bobot } 0 \\
\text { Konservasi mencapai } \\
90 \%\end{array}$} \\
\hline $\begin{array}{l}\text { Ground } \\
\text { Characteristics } \\
\text { and Cover }\end{array}$ & \multicolumn{2}{|c|}{$\begin{array}{c}\text { Bobot } 45 \\
\text { Berbatu, } \\
\text { berlempung,tanah } \\
\text { yg tak menyerap }\end{array}$} & \multicolumn{2}{|c|}{$\begin{array}{l}\text { Bobot } 40 \\
\text { Hutan terbuka } \\
\text { atau lahan } \\
\text { berumput, } \\
\text { tanaman }\end{array}$} & \multicolumn{2}{|c|}{$\begin{array}{c}\text { Bobot } 35 \\
\text { Lahan berumput } \\
\text { tanaman kayu } \\
\text { tektur tanah } \\
\text { medium }\end{array}$} & \multicolumn{2}{|c|}{$\begin{array}{c}\text { Bobot } 30 \\
\text { Wilayah tanaman } \\
\text { kayu rapat, lahan } \\
\text { pertanian dan } \\
\text { berkebun }\end{array}$} & & $\begin{array}{l}\text { Bobot } 10 \\
\text { ahan berpasir } \\
\text { atau tanah } \\
\text { engan agregat } \\
\text { baik }\end{array}$ \\
\hline
\end{tabular}

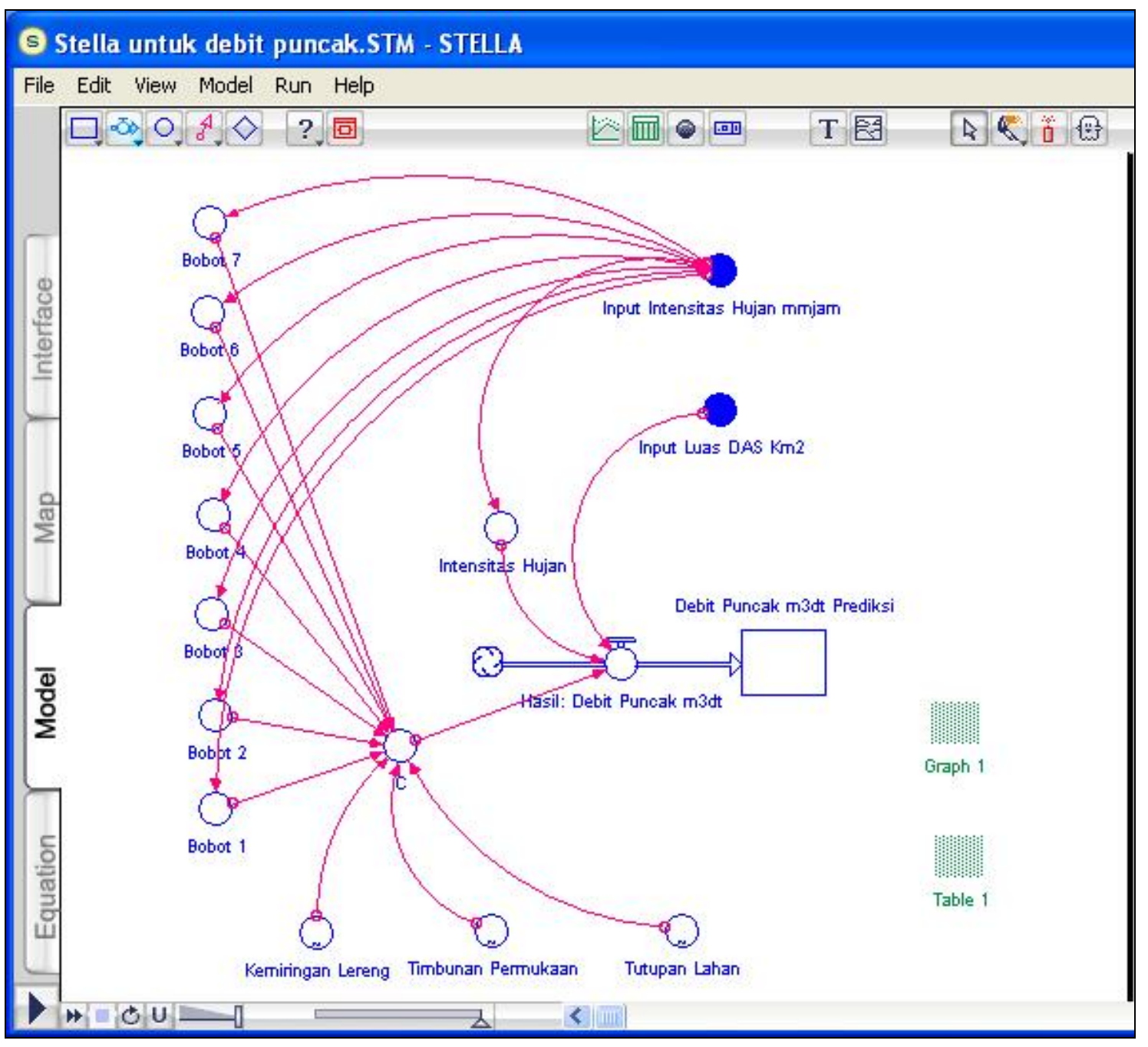

Lampiran 2. Model stella untuk debit puncak 


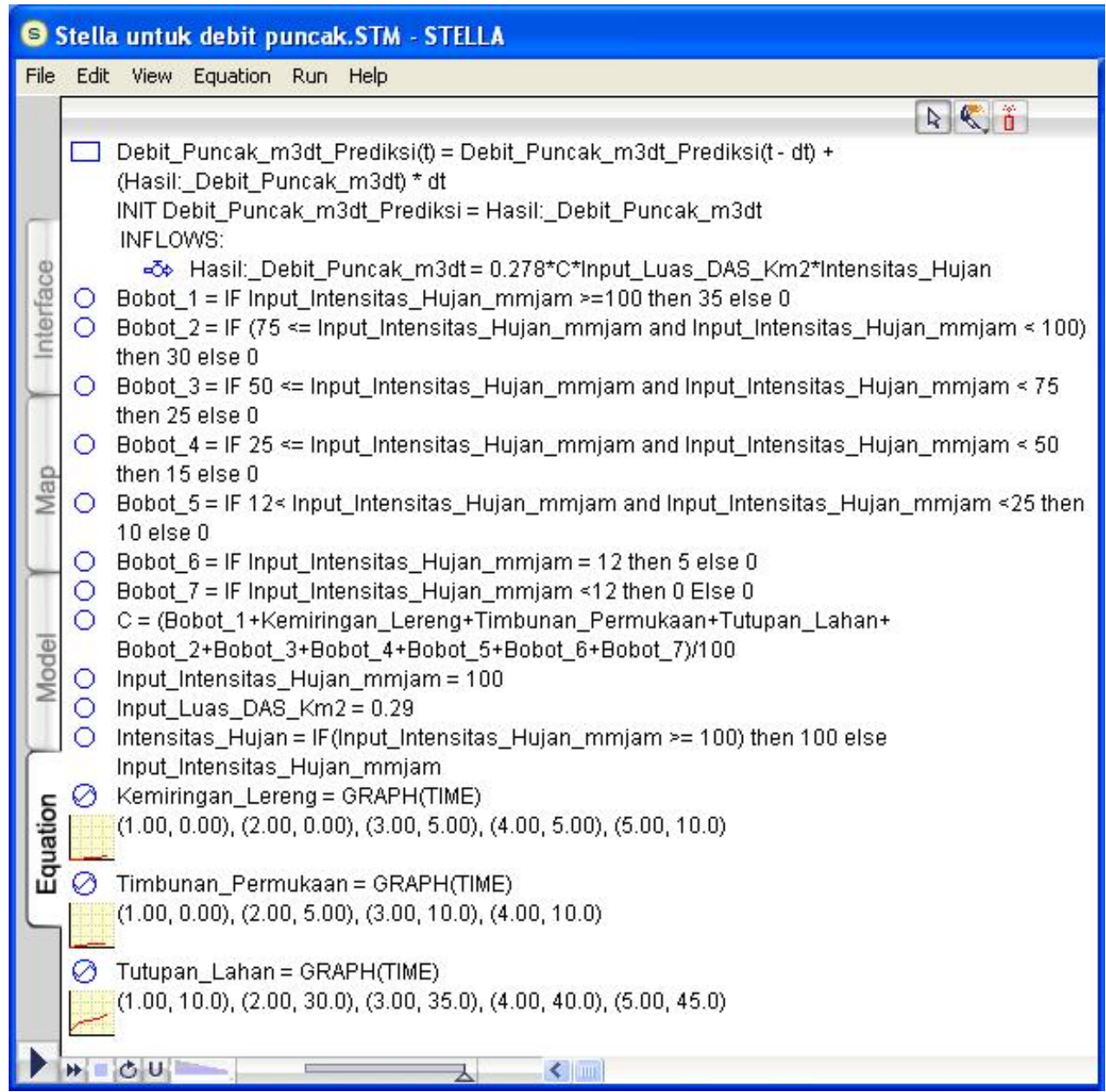

Lampiran 3. Kode program Model Stella untuk debit puncak

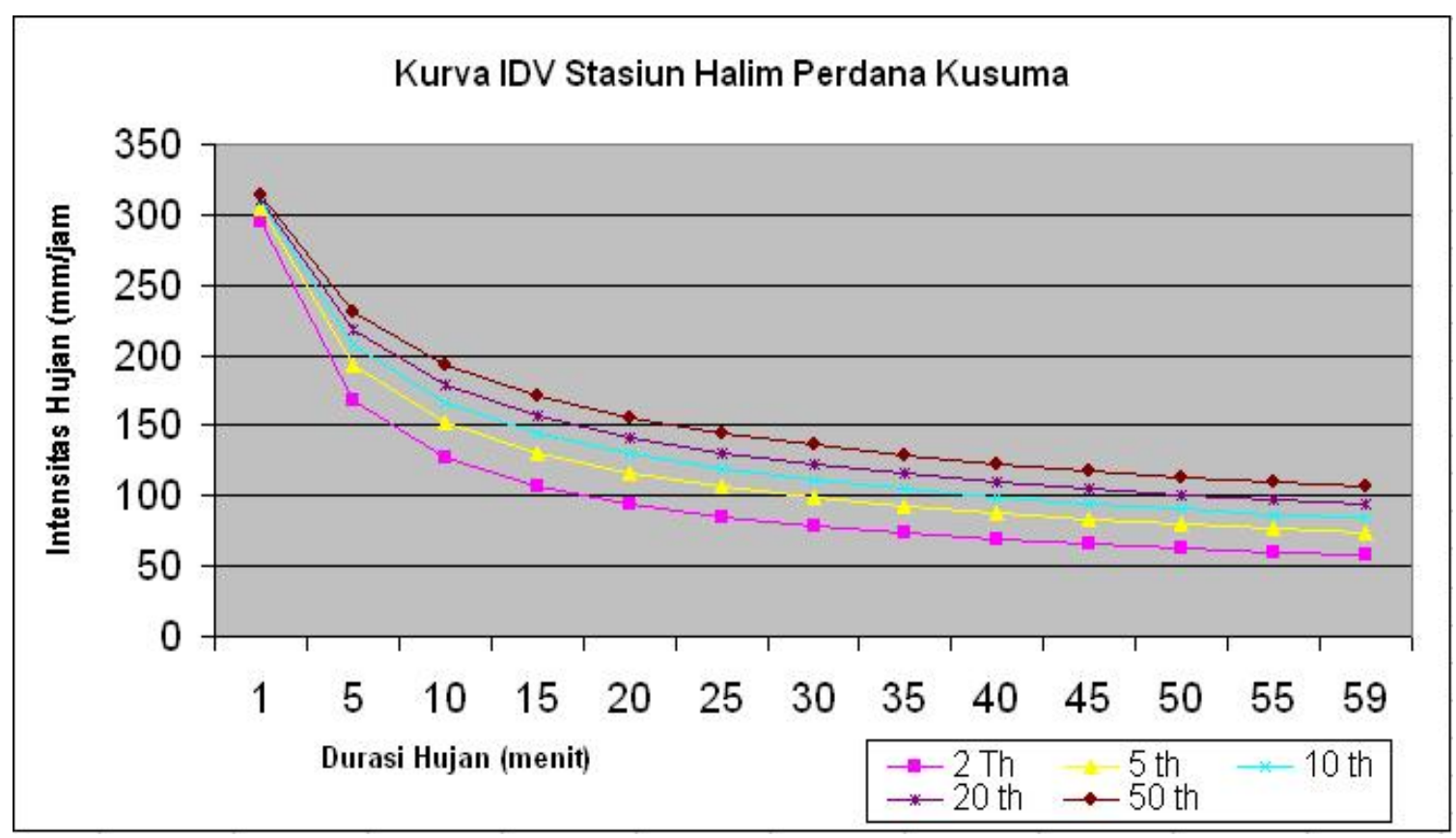

Sumber: Meliza, G.R., 2006

Lampiran 4. Grafik hubungan intensitas hujan dengan durasi dari berbagai periode ulang

Di Stasiun Halim Perdana Kusuma 


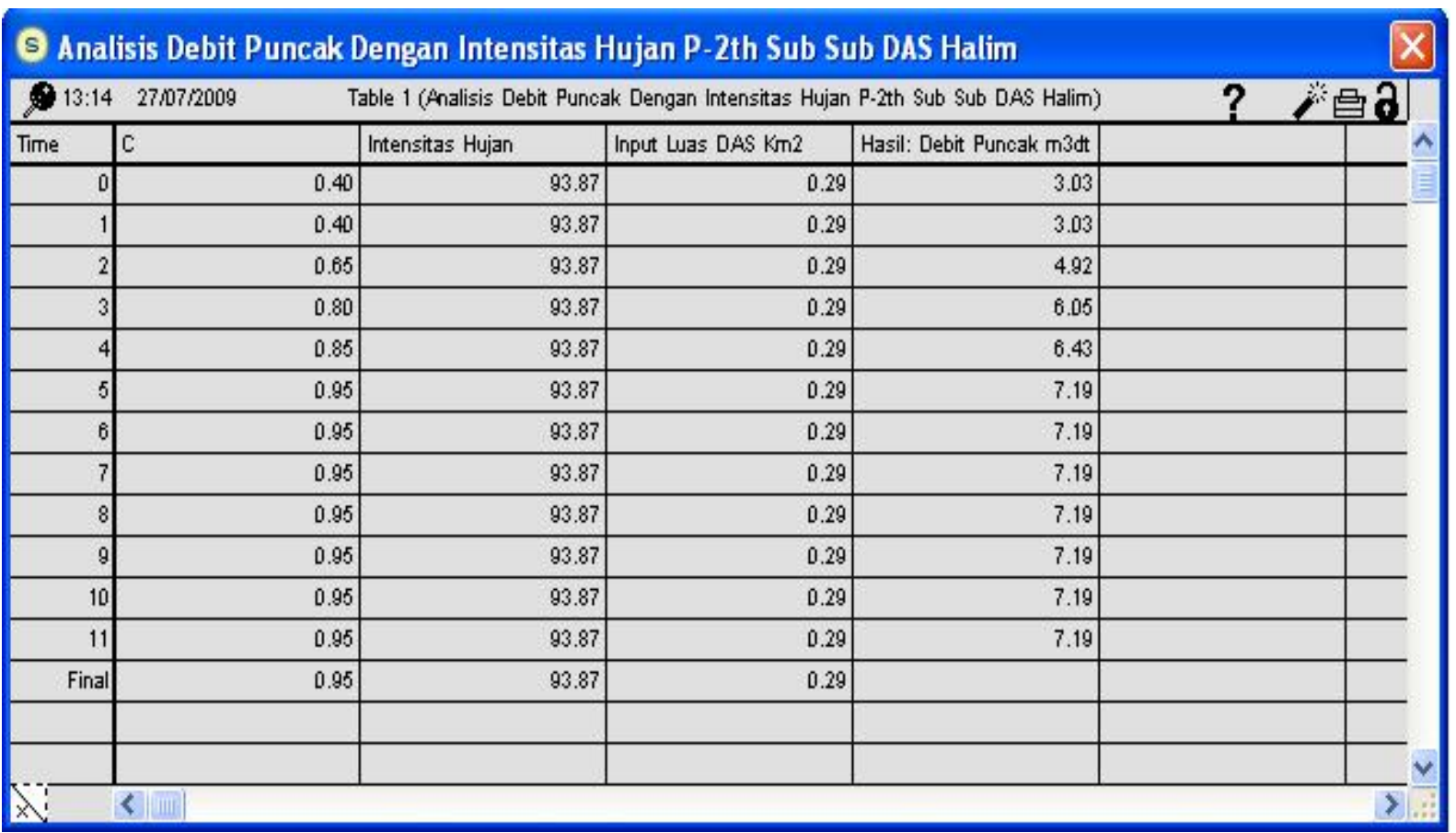

Lampiran 5. Debit puncak hasil menjalankan program Model SDDP pada sub-sub DAS Halim pada intensitas hujan 93,87 mm/jam periode ulang 2 tahun

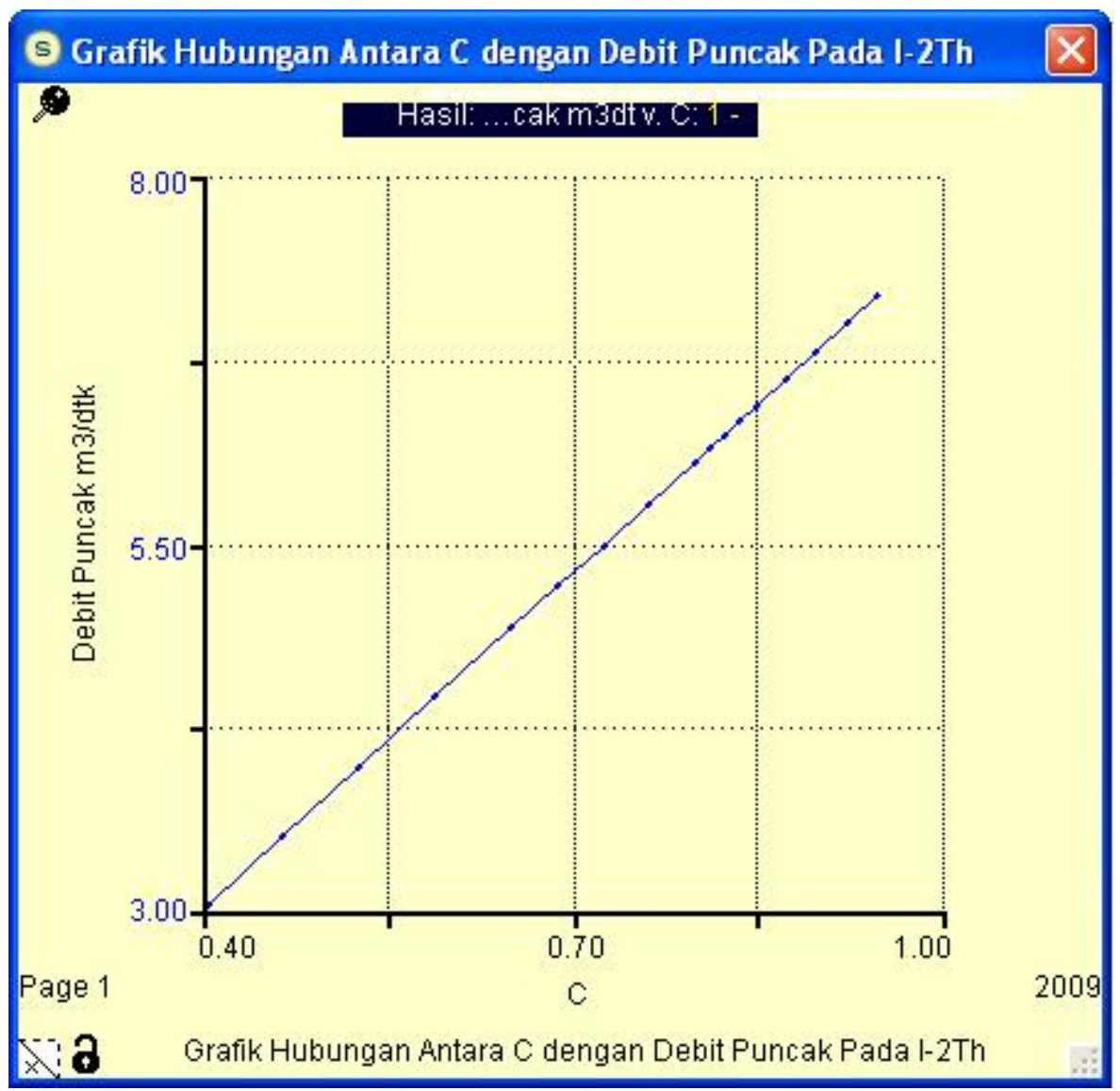

Lampiran 6. Hubungan antara $\mathrm{C}$ dengan debit puncak hasil menjalankan program Model SDDP pada sub-sub DAS Halim pada ilntensitas hujan $93.87 \mathrm{~mm} / \mathrm{jam}$ periode ulang 2 tahun 


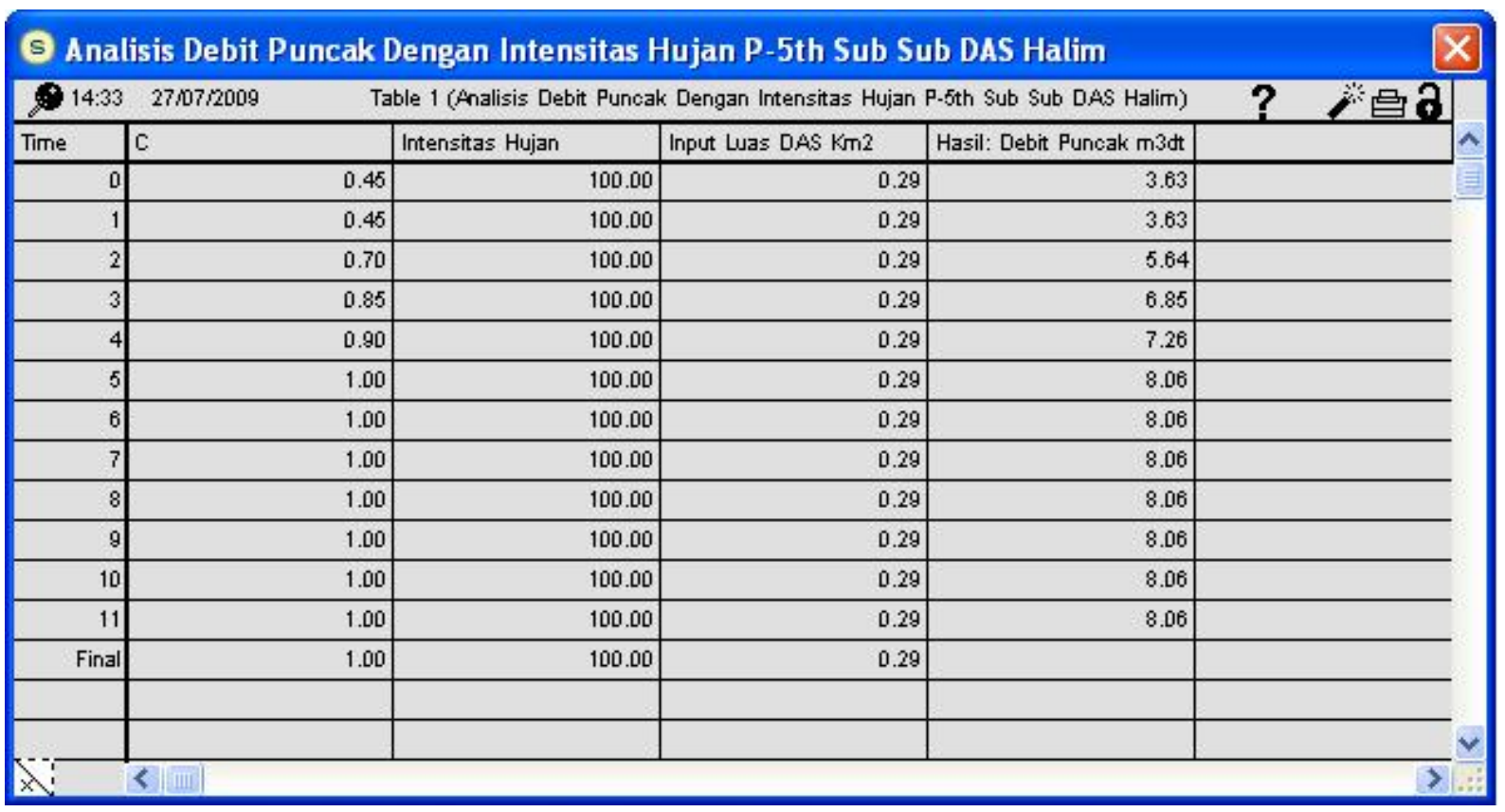

Lampiran 7. Debit puncak hasil menjalankan program Model SDDP pada sub-sub DAS Halim pada intensitas hujan $100 \mathrm{~mm} / \mathrm{jam}$ periode ulang 5 tahun

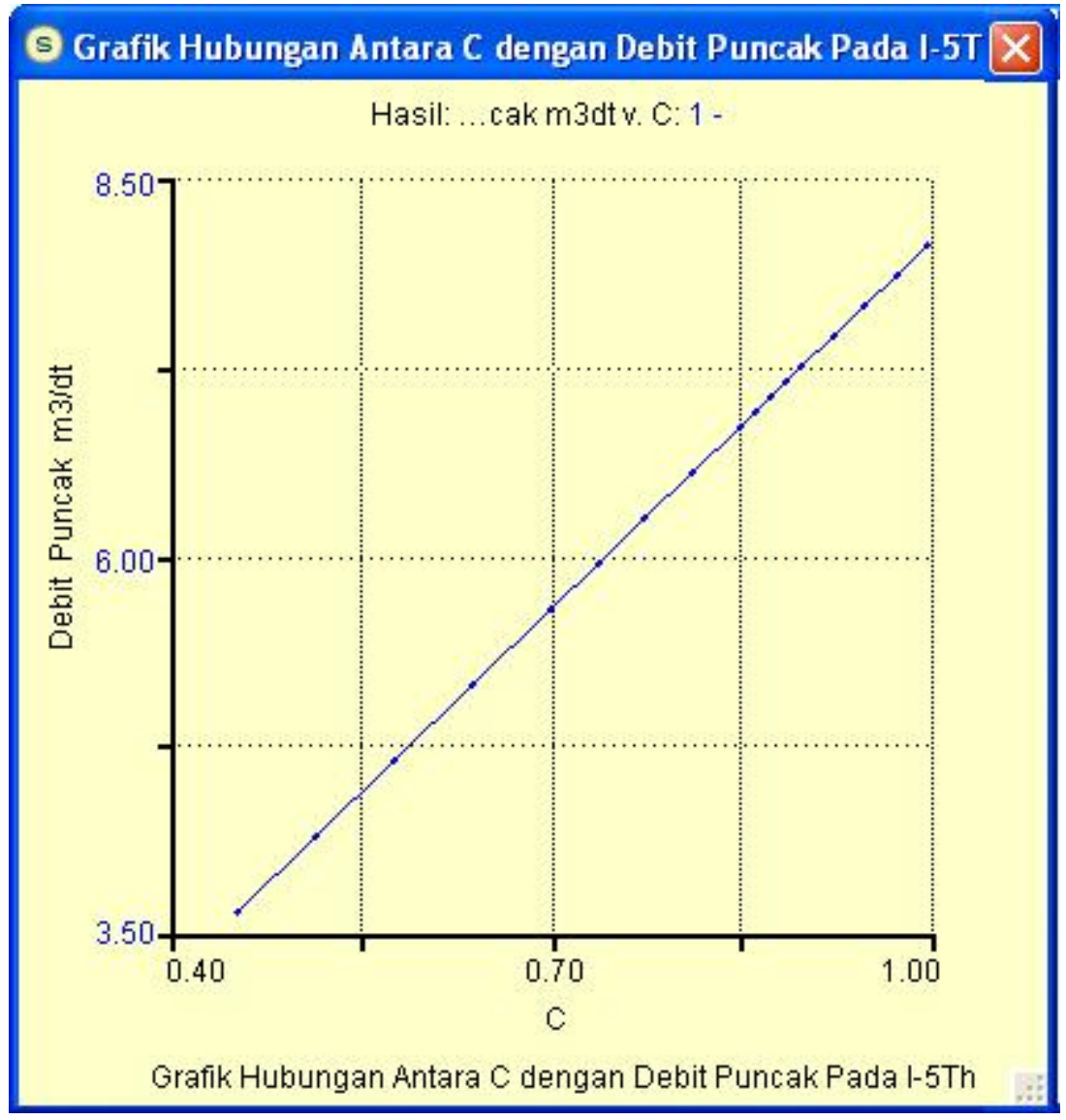

Lampiran 8. Hubungan antara $\mathrm{C}$ dengan debit puncak hasil menjalankan program Model SDDP pada sub-sub DAS Halim pada intensitas hujan $100 \mathrm{~mm} / \mathrm{jam}$ periode ulang 5 tahun 